Comet Morehouse, 1908 c.-From Mr. R. C. Johnson, one of the secretaries of the Liverpool Astronomical Society, we have received an enlarged copy of an excellent photograph of Morehouse's comet, taken by him, at his observatory at West Kirby, on November I5, 1908. The original photograph is one of a series of twenty taken with a $6 \frac{3}{8}$-inch reflector of 28 inches focal length, and received 42 minutes' exposure, from $5 \mathrm{~h}, 42 \mathrm{~m}$. to $6 \mathrm{~h}$. $24 \mathrm{~m}$. (G.M.T.).

The main streamer of the tail is very bright for a distance of about $40^{\prime}$ from the head, and extends to the edge of the plate, about $3^{\frac{1}{4}}$ degrees; at the end of the bright portion this streamer divides into three distinct branches, in each of which there are several convolutions. In addition to this, there are several shorter streamers, two of which curve towards the south.

Numerous observations of this comet, made between September 18 and October 30, 1908, at the Royal Observatory, Rome, are reported in No. 4293 of the Astronomische Nachrichten. (p. 331, December 27, 1908), and afford further evidence of the remarkable changes which took place in the form and brightness of the tail.

An ephemeris, covering the period January I3 to July 13, in ten-day intervals, appears in Circular No. I44 of the Harvard College Observatory. By the beginning of June, when the comet again reaches a declination observable in these latitudes, its computed brightness will be but about one-third that at the time of discovery.

A photograph of the spectrum of the comet, taken with the 8-inch Draper telescope on November 17, 1908, shows six broad bright bands which appear to coincide with $\mathrm{H} \zeta$, $\mathrm{H} \epsilon, \mathrm{H} \delta, \mathrm{H} \gamma, \mathrm{H} \beta$, and the band at $\lambda 4_{4}-473$, characteristic of the spectra of stars of the fifth type (Harvard College Observatory, Circular No. I45).

The Total Solar Eclipse of 19 I I April 28.- In a reprint from vol. lxix. of the Monthly Notices (R.A.S.), pp. 30-32, with which the author has favoured us, Dr. Downing sets out the conditions for the total solar eclipse of April 28, I9I1, as it will be observed at Neiafu, a port on the south-west coast of Vavau Island, one of the Tonga group. At this station totality will last about $3 \mathrm{~m} .37 \mathrm{~s}$. the altitude and azimuth (from N.) of the sun being $43^{\circ}$ and $49^{\circ}$ respectively. Mail steamers from Sydney call at Neiafu every four weeks, and the town is the headquarters of the Governor and of several English and German trading firms.

A Sixth Type of Stellar Spectra.-In Circular No. 145 of the Harvard College Observatory Prof. Pickering suggests that, for the purpose of facilitating reference to them, a number of stars already announced as having "peculiar" spectra should be assigned a class to themselves. This class would include a number of doubtful fourth-type stars, the spectra of which contain rays of much shorter wave-length than those of the normal fourth type; stars having spectra somewhat similar to those of the fifth type, but with the bright bands apparently reversed on a continuous spectrum; and stars of which the spectra are generally similar to the above, but show minor peculiarities.

It is proposed that the new class should be designated type VI., class $\mathrm{R}$, and Prof. Pickering publishes a list of fifty-one stars all of which would certainly be included in this class; none of these is brighter than magnitude $7 \cdot 5$. Several of the spectra of this type are reproduced in the circular, together with spectra of types I., IV., and V. for comparison.

The Astronomical and Astrophysical Society of AMERICA. - A brief résumé of the proceedings of this society, at its ninth meeting held at Put-in-Bay, Ohio, August 25-8, 1908, is published by Messrs. Jacoby and Sears in Science for December II, 1908 (N.S., vol. xxviii., No. 728). Two special committees were appointed, one to deal with the question of luminous meteors, the other to consider comets.

Brief abstracts of many of the papers read at the meeting are published in Science, but they are too numerous to be discussed here; mention of some of them has already been made in these columns.

No. 2045, vor. 70]
Spectroscopic Binaries.-In No, 5, vol. ii., of the Journal of the Royal Astronomical Society of Canada Mr. Plaskett announces that spectrograms taken at the Dominion Observatory, Ottawa, show that $\gamma$ Aquarii and Andromeda are spectroscopic binaries.

Spectrograms of the former, taken during July and August, 1908, indicate a variation in the radial velocity between $-40 \mathrm{~km}$. and $+23 \mathrm{~km}$., whilst spectrograms of the latter, taken in August and October, 1908, indicate a range from $-1 \mathrm{I} \mathrm{km}$. to $+32 \mathrm{~km}$.

The Variable Star U Geminorum.-The third volume of Recherches astronomiques de l'Observatoire d'Utrecht is devoted to a very full discussion, by M. J. van der Bilt, of observations of $U$ Geminorum, made between $185^{6}$ and 1907. This discussion occupies 115 pages, and is accompanied by twenty-seven plates giving the variously derived light-curves, one plate showing the normal curves of the long and the short maxima, and a final plate reproducing a chart of the stars surrounding this peculiar variable.

At the end of the discussion the author strongly emphasises the necessity for making constant observations of this star if its peculiarities and apparent anomalies are to be completely understood.

In the preface, Prof. Nijland states that whilst the first of these "Recherches" appeared in 1864, it is hoped that in future the volumes will appear at shorter intervals; vol. iv., dealing with observations of Jupiter, is already in the press.

The Heavens at a Glance.--Mr. Mee's handy card calendar for 1909 is similar to its predecessors in giving a great deal of useful astronomical information in a very compact form. For amateurs who wish to keep au courant with astronomical events, this calendar is an extremely useful aid, and may be obtained from Mr. Mee, Llanishen, Cardiff, for sevenpence, post free.

\section{SURVIVALS OF PAGAN BELIEFS AMONG THE INDIANS OF SOUTH CALIFORNIA.}

THE Luiseño Indians of South California, who with the kindred Diegueño tribe are the only survivors of those attached to the Franciscan missions, form the subject of a monograph by Miss C. B. DuBois, issued in the third. bulletin of the eighth volume of the ethnological publications of the University of California.

Though they have been exposed to European influence for more than a hundred years, and have lived for nearly two generations under rigid Christian discipline, it is remarkable that so many of their pagan beliefs and customs have survived. It is still more noteworthy that, about a hundred and twenty years ago, a pagan missionary movement extended from them to the Diegueño tribe, among whom the new cult which centres round the personality of Chungichnish was introduced. This new faith, like others which have extended beyond their original home, had every requisite of a conquering religion-a distinct and difficult rule of life demanding obedience, fasting, and self-sacrifice-and it enforced its commands by an appeal to the fear of punishment, a threat that avengers in the shape of stinging weeds, the rattle-snake and the bear would punish neglect of its observances.

The most important of the rites connected with the Chungichnish cultus is that of Toloache, or the initiation of youths and girls. In the case of the former, the candidates, in a state of nudity, are dosed with a decoction of the jimson-weed (Datura meteloides), which contains a powerful narcotic and excitative principle. After the intoxication produced by this drug has passed away, the secret dances of the tribe are performed and the mystic songs are sung. The Shaman who conducts the proceedings asserts that he is possessed of magical powers, and the initiates are instructed to imitate his feats. During the dance the performers appear to speak in the tongues of beasts and birds, a rite possibly connected with a belief in personal totem animals or guardian spirits, which up to quite recent times survived among this people. These rites are followed by a fast from salt and meat sometimes lasting two or three weeks, and meanwhile the youth is instructed in the tribal code of etiquette and morals. $\mathrm{He}$ is told, for instance, that no one should eat immediately 
on rising lest the spirit which was absent from his body in sleep should be unable to return. On the same principle, on return from an expedition into the hills he must defer eating. so as to permit the wandering spirit to rejoin its mortal body.

This initiation rite is accompanied by an elaborate symbolism, of which Wanuwat, or the sarred net, and a form of painting or modelling in sand are the most prominent features. The net is said to symbolise the Milky Way, a prominent feature in the night sky of that region, which is regarded as the home of the dead; and the main idea seems to be based upon an attempt to free the departed spirits from this earth, and to prevent their return by binding them in the net of the Milky Way, The sand painting may perhaps best be described as a cosmological model in which the tribal conception of the relation of this world to the heavens is portrayed.

The annual commemorative rite for the dead is performed over images representing the departed, a custom common to the Hindus and other savage or semi-savage races. Singing and dancings, with whirling of the builroarer, precede the burning of the images, in some cases the clothing and ornaments being consumed, in others removed by the friends. like the rite of the sacred net. the intention seems to be to expel the spirits of the de:ad from the neighbourhood of the living.

The Creation legends of the tribe, now for the first time fully recorded by Miss Dubois, are of considerable inportance, and must be taken into account by all studeniof comparative myihology. In the beginning existed on? Kivish Atakvish, the Void, who was follower by Whaik:, Piwkut, "the whitish gray," who (reated two great round balls, which were mate and fenmle. The union of Sky and Farth then produced the First Jeople, now represented by the massic mortar, wampun striners, the mail used in the death rites, and other sacred objects, anim:-l and vergetable. Then appears a deified hero, Oniot, who is done to death by Wahawut, the witch, and, as in the Hindu Yama saga, death thus entered the world. Beside these is a group of interestings sky myths. The remarkable clement in these lecrends is that they imply a sue ression of births or existences, some of them psychic, us to the present hardly lenown in native American thousht, and Mr. Frochere the editor of the report, groe's so far as to suggest that they represent Oceanic or Asiatic influener. But it must be renembered that these rites and legend. have been for the first time recorded at a very late period in the history of the tribe, when it hat been for at lon:r priod exposed to foreign influences. Possibly much of this elaborate ssmbolism is of native orisin, but the inte... pretation of them now explained by the fow survivors of the tribe who were initiated into the meteries is so:mrwhat obscure, and may not be really primitive.

A strong case can undoubtedly be mide out for the independent origin of native Ainerican culture, and the theory of early historical relations between its races and those of Asia is beset by enormous difficulties. On the whole, it seems probable that the interpretation of these luiseno myths will not lead to a modification of the view venerally accepted by anthropologists, that they are of indigenous growth. 'The question is, however, not frop from difficults. They are in themselves of great interest. deserve attentive study, and their collection is another debt which ethnologists owe to the enterprise of the anthropological department of the Eniversity of California.

\section{FIEI.D NATLRAL, IISSTORY.}

TO the Transactions of the Edinburgh Field Naturalists' and Microscopical Society, wol. vi., part i., Mr. J. C Adam has contributed a charmingly written and exqui sitely illustrated account of the bird-life of an outlying, and consequently little frequented, island in the Outer Hebrides group. After remarking how little of interes in the way of bird-life is noticeable from the single village, the author procerds to give his experiences of the purple sandpiper, of which several specimens, in what appeared to be the breedins-plumage, were observed on the hish ground of the interior, where: it was hoped they would lee found nesting. Careful search failed, however, to bring eggs to light, while the artions of the birds themselves did not suggest that they were breeding. On the sedi-cliffs the birds absolutely swarmed. The lower levels, at a height of 100 feet, or occasionally 200 feet, form the resort of the oyster-catcher. ". Beyond the ovster-catchers" territory was the domain of the birg-gulls-the herrins and the lesser black-backs; in fact, their respective spheres of influence encroached upon one another, and the? clamorous cloud of swirling gulls, which even encanopied the intruder, were invariably 'threaded' by the highpitched, piercing notes of a 'sea-pie.' The herring gull was by far the most abundant species. . . When you had passed within the dominion of the gulls, you were on the brink of the cliff-wall, and from some coign of vantage might look down on the perpetual wonder and prodisatity of a rock-fowl city. For sheer impressiveness you were perhaps wise to choose a stance as far down as you could reach in one of the great chasms which the ceaseless srind of the tide and the stress of . Itlantic weather had grnawed

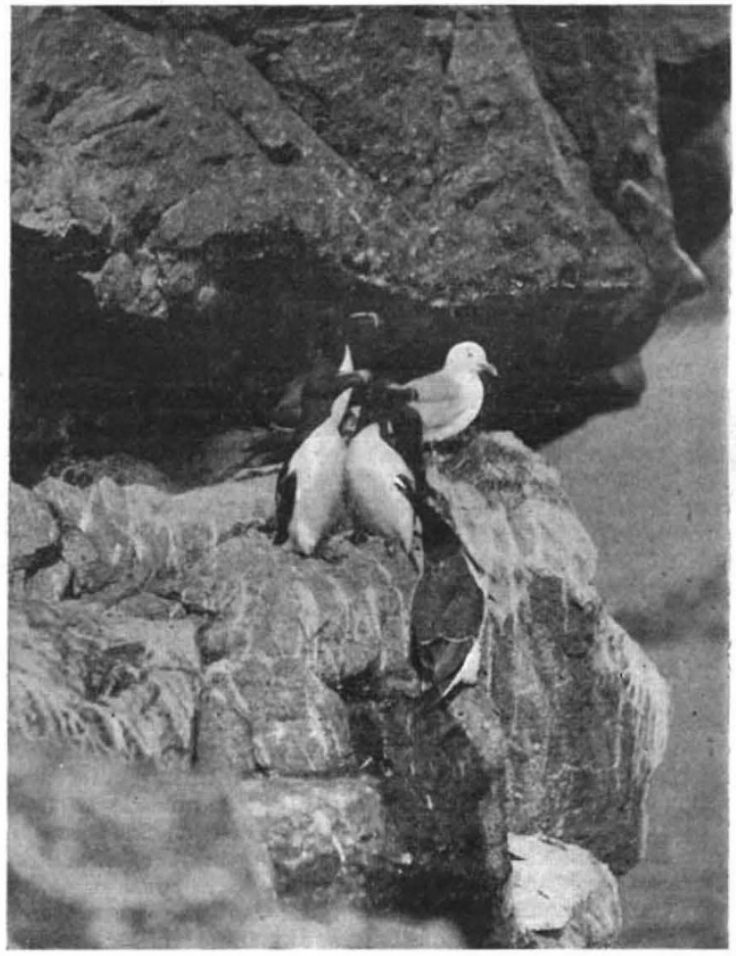

Razorbills and Kittiwake. From the "Dird life of an Outer Island."

into the very vitals of the island." One of the illustrations from this paper is here reproduced.

To the same Transactions Mr. R. Service contributes some interesting observations on variation in the mole. The largest male obtained measured $7 \frac{3}{3}$ inches in length, but an inch less than this still indicate: a large individual $5 \frac{1}{2}$ inches is about the average for the female, the maxiinum observed being $6 \frac{1}{1}$ inches. Great variation in the tint of black individuals is noticeable. As regrards more striking colour-variation, the commonest abnormality is creamcolour, ranging from pale creasm to deep rusty yellow, but a comparatively common phase shows a patch of vellow or rufous on the breast or abdomen, or on both. In some instinces the lisht area extends over the whole of the under-parts, while in other cases it take's the form of a narrow or broad line down the middle of the same resion. but in all individuals the light area has a longitudinal extension, and it is always sharply defined from the dark parts. A really white nole is very rare. There seems little doubt that the tendency to colvar-variation runs in partictelar families of moles. 